\title{
Etiology and Risk Factors for Developing Knee Osteoarthritis
}

\author{
Monshefa Akhter ${ }^{1}$ and Hamida Khanum ${ }^{2 *}$ \\ ${ }^{1}$ Emergency Operation Theatre 105, Dhaka Medical College Hospital, American International University-Bangladesh (AIUB), \\ Bangladesh
}

${ }^{2}$ Parasitology Branch, Department of Zoology, University of Dhaka, American International University-Bangladesh (AIUB), Bangladesh

*Corresponding author: Hamida Khanum, Parasitology Branch, Department of Zoology, University of Dhaka, American International University, Bangladesh

\section{ARTICLE INFO}

Received: 幽 March 04, 2021

Published: 彗 March 15, 2021

Citation: Monshefa Akhter, Hamida Khanum. Etiology and Risk Factors for Developing Knee Osteoarthritis. Biomed J Sci \& Tech Res 34(3)-2021. BJSTR. MS.ID.005567.

Keywords: Age; BMI; Osteoarthritis; Occupational Knee Bending; Risk Factors

\begin{abstract}
Osteoarthritis $(\mathrm{OA})$ is a chronic degenerative joint disease and is the commonest form of arthritis. It progresses slowly with usual signs and symptoms being pain, enlarged and deformed joints as well as limitation of the range of motion. It is also a leading cause of disability affecting $60-70 \%$ of the older population. It usually affects the hand and large weight bearing joints, often the knee and the hip. A hospital based cross sectional study was carried out to study the risk factors of Osteoarthritis of Knee among patients attending Orthopaedics OPD. All patients aged between 40 and 65 years were included in the study. Out of 71 respondent, $41(57.7 \%)$ were female and $30(42.3 \%)$ were males. Out of 71 respondents, 30 (42.3\%) were Diabetic and 41 (57.7\%) non- Diabetic, 33 (46.5\%) were Hypertensive and 48 (53.5\%) non- Hypertensive. OA increased with age and BMI. Risk factors like family history, history of knee injury and occupational knee bending were seen in only few of our study subjects. There is a positive association of the Diabetes mellitus and knee osteoarthritis, there is need to spread awareness among people to adopt preventive measures at an earlier age along with healthy lifestyle to reduce the body weight and hence the risk of OA.
\end{abstract}

\section{Introduction}

Osteoarthritis is a chronic joint disorder in which there is progressive softening and disintegration of articular cartilage accompanied by new growth of cartilage and bone at the joint margins (osteophytes) and capsular fibrosis [1]. In its most common form, it is with age, in the majority of cases the Osteomeans bones [2] and arthritis mean inflammation of a joint (Hilt and Cogburn, 1994) or "osteoarthritis (OA) = can also be called 0- old age, A- arthritis" [3]. It is a chronic joint disorder [4]. But it is considered to be a degenerative and progressive condition affecting synovial joints [5] characterized by focal loss of articular hyaline cartilage simultaneous proliferation of new bone with remodeling of joint contour [6]. Osteoarthritis occurs due to the breakdown and eventual loss of the cartilage of one or more joints [7]. OA commonly affects the hands, feet, spine and large weight bearing joints such as the hips and knees [8]. Patient with knee OA reported pain and difficulty in everyday activities such as ascending and descending stairs, squatting, kneeling, rising from a chair and getting in and out of a car [9].

\section{Osteoarthritis in the Context of Bangladesh}

In Bangladesh, knee osteoarthritis is one of the familiar disabling diseases affecting both elderly male and female [10]. Osteoarthritis has a significant impact on our society because it is the most prevalent musculoskeletal disorder. Most of the available literature shows that there is no effective treatment for osteoarthritis [11]. It is known that knee joint probably is the most complicated joint in the human body [12]. Functionally, the knee joint is a condylar and modified hinge joint [13]. Osteoarthritis of the knee is the most often occurring disease of all other joint diseases [14]. In Bangladesh, the prevalence of osteoarthritis and that is $10,392,681$ people are affected by osteoarthritis (Statistics 
by Country Osteoarthritis, 2005, 2006). In developed countries knee osteoarthritis is the most leading causes of chronic disability among the elderly. The knees are mainly the large joints involved in the osteoarthritis [15]. As a result of the degenerative changes the disease may also be accompanied by abnormalities in excitability of the nerve endings located in and around the joint tissue and by abnormalities of motor activity.

\section{Etiology and Risk factors}

According to Osteoarthritis 2006, the exact cause of the osteoarthritis in knee is unknown. The chances of getting osteoarthritis seem to increase with age. Overweight can increase the risk of getting osteoarthritis. Injury to a joint or repeated overuse can damage the cartilage and leading to osteoarthritis. Other types of arthritis can also damage joints and lead to osteoarthritis. Chitnavis and Carr (2002) claimed that OA are idiopathic in most of cases. There are varieties of risk factor for the development of $\mathrm{OA}$ which are ageing, gender, race, obesity, congenital and acquired deformity, inheritance, injury and joint uses have all been implicated in disease production. According to Hurley (2002) stated that related to the age, joint and muscles, hormonal changes (particularly in women following menopause), excess body weight, congenital abnormalities and previous joint injury leading to muscle weakness and joint instability are the causes of OA. There is some evidence that the synovial joints most commonly affected are under evolved for the activities they are routinely subjected to, i.e., knees and hips for weight bearing and joints of the hands for pincer grip activities. This may be due to increase load, e.g., in deformities that affecting the lever system around the joint or to a reduction of the articular contact area, e.g., with joint in congruity or instability (Solomon et al. 2001). Risk factors were evaluated: age (in years), sex, education (in years), BMI (kg), physical workload, smoking, leisure time physical activity and injury history (yes/no) [16].

\section{Classification of Osteoarthritis}

Chitnavis and Carr (2002) classified OA based on etiology which is familiar to clinicians and subdivided OA into' Primary' for which the cause of disease production in unknown and 'Secondary' which is related to some factors such as injury and deformity. OA classified into 'Primary' (when there is no obvious antecedent factor) and 'Secondary' (when it follows a demonstrable abnormality) in somewhat artificial [17].

\section{Primary Osteoarthritis}

This is less common type of osteoarthritis. It is also called Nodal Generalized Osteoarthritis (NGOA). It predominantly affects women. In the human body, the knee joint is commonly affected by osteoarthritis [18]. Though exact cause is not known [19] the following factors are suspected to, causation of primary OA are age, obesity, genetics, occupation involving prolonged standing, sports, multiple metabolic disorders [20]. Another study shows the factors that are responsible for primary osteoarthritis are crystals in joint fluid or cartilage, high bone mineral density, injury to the joint, peripheral neuropathy, joint hyper mobility [21].

\section{Secondary Osteoarthritis}

Thomson, et al.(1991) stated that secondary osteoarthritis arises as consequences of various conditions. These are as follows: Trauma after severe injury, resulting in fractures of the joint surfaces, Dislocation and Infection. The causes of secondary osteoarthritis of the knee are as valgus and virus deformities of the knee, Rheumatoid arthritis, infection, TB, hyperparathyroidism, overuse of intra articular steroid therapy [22]. Repeated minor trauma may lead to micro fractures and subsequent OA. Occupational factors are thought to be important in the development of secondary OA. Hemophillia, acromegaly and hyperthyroidism all predispose joints to secondary OA [23].

\section{Statement of Problem}

Knee osteoarthritis is prevalent musculoskeletal condition affecting older people, producing pain, physical disability, and reduced quality of life. It also imposes a considerable economic burden on the health care system [24]. Osteoarthritis is the most ordinary types of joint disease and a frequent cause of pain and physical disability [25]. Osteoarthritis affects $12 \%$ of the population aged 25 to 74 years. Over the 70 years, radiographic osteoarthritis in the small joint of the hand is present in more than $80 \%$ of the population. Up to two- third of those with knee osteoarthritis and one-third of those with hip osteoarthritis have symptoms related to their disease [26]. Local vascular changes accompanied by ischemia of subchondral and junta chondral bone. The profound anatomical and physiological alterations may produce signs of inflammation. Osteoarthritis is the most prevalent of the rheumatic diseases, affects more than $40 \%$ of western world adults with the knee being one of the most commonly afflicted joints [27]. The overall incidence of newly diagnosed osteoarthritis of the hip and knee is estimated at 200/100000 person per years [28]. In 1990, estimated 15\% (37, 9 million persons) of the U.S. population had arthritis. Estimated prevalence rates were $49.4 \%$ for aged persons greater than or equal to 65 [29].

\section{Justification of the Study}

Knee osteoarthritis is one of the most prevalent rheumatic disorders in the Asia-Pacific region. Identification of risk factors is very important for development of strategies for primary and secondary prevention of knee osteoarthritis. The development of osteoarthritis is determined by age, genetic predisposition, previous injury, chronic stress across the joint, and abnormal mechanical forces caused primarily by obesity [30]. Statistics by Country Osteoarthritis (2005) stated that in Bangladesh 10,392,681 people was affected by osteoarthritis in 2004. Some studies have shown that obesity is associated with osteoarthritis in non-weight- 
bearing joints such as the small joints of the hand, which might indicate metabolic effects of overweight involved in the arthritic process and did not find any association between metabolic factors such as serum cholesterol, blood pressure or diabetes, and the development of knee osteoarthritis [31].

\section{Methods and Materials}

Study design and population: Cross sectional study design used to identify the risk factors of developing knee osteoarthritis. Patient with knee and major joints problem attended to Sure Cell Medical Center, Gulshan1, Dhaka for physiotherapy and treatment from different area of Bangladesh. The study was conducted from May 2018 to December 2018. Simple random sampling technique (probability sampling) was applied for determining sample size and data collection. The data was collected from primary sources. Every month, 5-10 interviews were conducted via Face to face interview. The questionnaire was administered to assess the sociodemographic characteristics, disease and family history, lifestyle and physical activities of the respondent. Data management and Analysis plan: SPSS and MS-EXCEL was used for the data analysis. Weight was evaluated with the help of formula of Z-Score of weightfor-age. The Standard Deviation (SD) equal and or less than -3 was considered as severe underweight, -2.99 to -2.00 SD was considered as moderate underweight and -1.99 to -1 SD was considered as mild underweight. Chi-square was done to test the association between underweight and factors to determine the relationship.

\section{Results}

The present study has been done on the risk factors of developing knee osteoarthritis. A total of 71 respondents in the age group of 40-65 years and confirmed both clinically and radiologically for OA attending Surecell Medical Orthopedics OPD were included in the study. Out of 71 respondent, 41 (57.7\%) were female and 30 (42.3\%) were males Table 1). Among the respondent the highest percentage of the respondents were between 55-59+ years (40.8\%) old following by the age between 50-54 years were $25.4 \%$. Out of which there were only $19.7 \%$ of $45-49$ years old, $14.1 \%$ of the respondents were of the age group 40-44 years (Figure 1). Out of 71 respondents, 27 (38.0\%) have knee osteoarthritis and 44 (62.0\%) have no sign of Knee osteoarthritis. Among the respondent majority of the respondent's 54 (76.1\%) have no past history of knee injury. Only few 17 (23.9\%) have their past history of knee injury. From the Table 1, it was observed that, there is no association of the gender and knee osteoarthritis. In the present study, among 41 female respondents 18 had knee osteoarthritis and similarly, among 30 of the male respondents, 9 had knee osteoarthritis (Table 1).

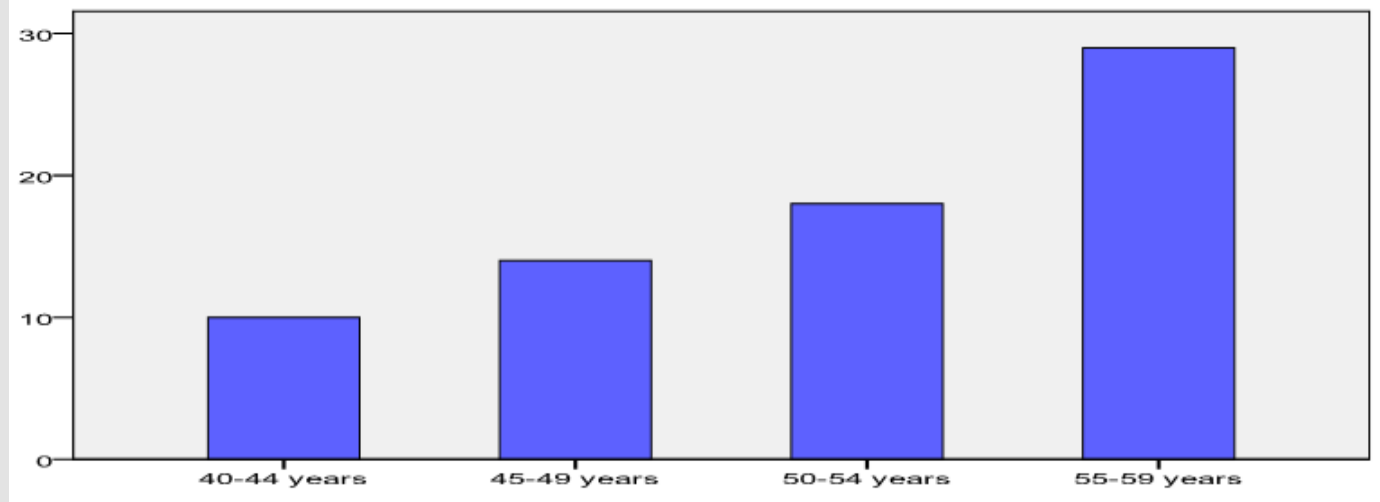

Figure 1: Age-groups of the Respondents.

\section{Diabetic Condition and BMI Level of the Respondents}

Out of 71 respondents, $30(42.3 \%)$ were Diabetic and 41 (57.7\%) non- Diabetic, 33 (46.5\%) were Hypertensive and 48 (53.5\%) non- Hypertensive. Among the respondent majority of the respondents 39 (54.9\%) had normal BMI, and 24 (33.8\%) were obese and only 8 (11.3) found overweight (Figure 2). In the present observation it was evident that the association of gender and knee osteoarthritis of the respondent (Table 1). The chi-square has been done to see the association of the gender and knee osteoarthritis. Where, Pearsons Chi-square ' $\mathrm{P}$ ' value $(\mathrm{P})=0.233$. From the above table we can understand there is no association between gender and knee osteoarthritis. For the association between gender and knee osteoarthritis, ' $\mathrm{P}$ ' value was 0.233 , i.e., it is not significant.
We can say gender and knee osteoarthritis do not have any association. For association $\mathrm{P}$ value should be smaller than 0.05 i.e. $(\mathrm{P}<0.05)$. But here, $0.233>0.05$. So, we can say that gender and knee osteoarthritis are not associated. Here, we can also say that gender is not a risk factor for developing knee osteoarthritis (Table 2). From the Table 3, it is evident that, the association of the age and knee osteoarthritis. The highest 29 respondents were in 55-59 years of age group, where 17 had knee osteoarthritis, similarly, among 18 respondents of 50-54 years age group, 8 had knee osteoarthritis and 10 had not. On the other hand, among 14 respondents of age between 45-49 years, 1 had knee osteoarthritis and 13 had not. And among 10 respondents of age between 40-44 years, 1 had knee osteoarthritis and 9 had not. 


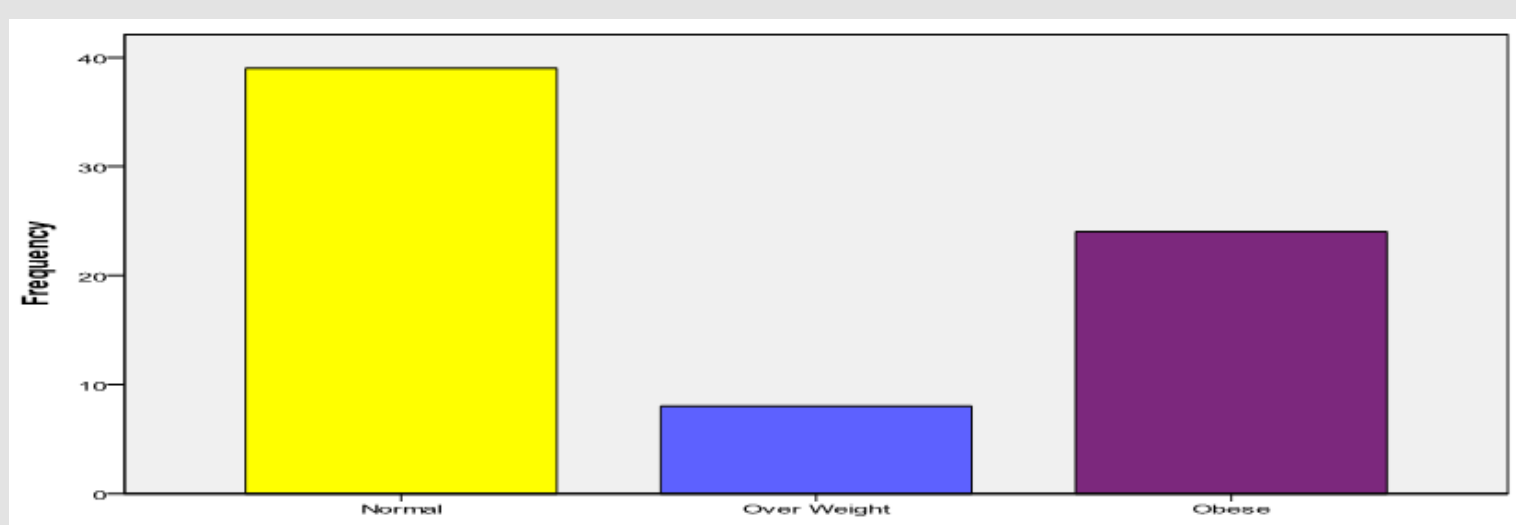

Figure 2: BMI level of the Respondents.

Table 1: Association between gender and knee osteoarthritis.

\begin{tabular}{|c|c|c|c|c|}
\hline \multicolumn{2}{|c|}{} & \multicolumn{2}{|c|}{ Knee Osteoarthritis } & \multirow{2}{*}{ Total } \\
\cline { 3 - 5 } \multicolumn{2}{|c|}{} & Yes & 23 & 41 \\
\hline \multirow{3}{*}{ Sex } & Female & 18 & 21 & 30 \\
\cline { 2 - 5 } & Male & 9 & 44 & 71 \\
\hline
\end{tabular}

Table 2: Chi-square tests of gender and knee osteoarthritis.

\begin{tabular}{|c|c|c|c|c|}
\hline \multicolumn{5}{|c|}{ Chi-Square Tests } \\
\hline & value & Asymp. Sig. (2-sided) & Exact Sig. (2-sided) & Exact Sig. (1-sided) \\
\hline Pearson Chi-Square & 1.421 & .233 & & \\
\hline Continuity Correction & .892 & .345 & & \\
\hline Likelihood Ratio & 1.438 & .230 & .323 & .173 \\
\hline Fisher's Exact Test & & & & \\
\hline Linear-by-Linear Association & 1.401 & .237 & & \\
\hline N of Valid Cases & 71 & & & \\
\hline
\end{tabular}

Regarding the association of age and knee osteoarthritis of the respondent, the chi-square has been done to see the association of the age and knee osteoarthritis. Where, Pearsons Chi-square ' $\mathrm{P}$ ' value $(\mathrm{P})=0.002$. From the above table we can understand there is association between age and knee osteoarthritis. For the association between age and knee osteoarthritis, ' $\mathrm{P}$ ' value was 0.002 . I.e., it is significant. We can say age and knee osteoarthritis do have association. For association $\mathrm{P}$ value should be smaller than 0.05 i.e. $(\mathrm{P}<0.05)$. Here, 0.002> 0.05. So, we can say that age and knee osteoarthritis are associated. Here, we can also say that age is risk factor for developing knee osteoarthritis (Tables 3 $\& 4$ ). Regarding the association of the Diabetes mellitus and knee osteoarthritis, among 30 Diabetes mellitus positive respondents 16 had knee osteoarthritis and 14 had not. On the other hand, among 41 Diabetes mellitus negative respondents 11 had knee osteoarthritis and 30 had not. The present study indicate that there is an association of Diabetes mellitus and knee osteoarthritis of the respondent. The chi-square has been done to see the association of the Diabetes mellitus and knee osteoarthritis. Where, Pearsons Chi-square ' $\mathrm{P}$ ' value $(\mathrm{P})=0.023$. For the association between Diabetes mellitus and knee osteoarthritis, ' $P$ ' value was 0.023 . I.e., it is significant. We can say Diabetes mellitus and knee osteoarthritis do have association. For association $P$ value should be smaller than 0.05 i.e. $(\mathrm{P}<0.05)$. Here, $0.023>0.05$. So, we can say that Diabetes mellitus and knee osteoarthritis are associated. Here, we can also say that Diabetes mellitus is risk factor for developing knee osteoarthritis (Tables 5 \& 6).

Table 3: Association between age and knee osteoarthritis.

\begin{tabular}{|c|c|c|c|c|}
\hline \multicolumn{2}{|c|}{} & \multicolumn{2}{c|}{ Knee Osteoarthritis } & \multirow{2}{*}{ Total } \\
\cline { 3 - 5 } \multicolumn{2}{|c|}{} & Yes & No & \\
\hline \multirow{3}{*}{ age } & $40-44$ years & 1 & 9 & 10 \\
\cline { 2 - 5 } & $45-49$ years & 1 & 13 & 14 \\
\cline { 2 - 5 } & $50-54$ years & 8 & 10 & 18 \\
\cline { 2 - 5 } & $55-59$ years & 17 & 12 & 29 \\
\hline \multirow{2}{*}{ Total } & 27 & 44 & 71 & \\
\hline
\end{tabular}


Table 4: Chi-square tests of age and knee osteoarthritis.

\begin{tabular}{|c|c|c|c|}
\hline \multicolumn{3}{|c|}{ Chi-Square Tests } \\
\hline Pearson Chi-Square & Value & df & Asymp. Sig. (2-sided) \\
\hline Likelihood Ratio & 14.533 & 3 & .002 \\
\hline Linear-by-Linear Association & 16.543 & 3 & .001 \\
\hline N of Valid Cases & 12.799 & 1 & .000 \\
\hline
\end{tabular}

Table 5: Association between Diabetes mellitus and knee osteoarthritis.

\begin{tabular}{|c|c|c|c|c|}
\hline \multicolumn{2}{|c|}{} & \multicolumn{2}{|c|}{ Knee osteoarthritis } & \multirow{2}{*}{ Total } \\
\cline { 3 - 5 } \multicolumn{2}{|c|}{} & Yes & 14 & 30 \\
\hline \multirow{2}{*}{ DM } & Yes & 16 & 30 & 41 \\
\cline { 2 - 5 } & No & 11 & 44 & 71 \\
\hline
\end{tabular}

Table 6: Chi-square tests of Diabetes mellitus and knee osteoarthritis.

\begin{tabular}{|c|c|c|c|c|c|}
\hline \multicolumn{7}{|c|}{ Chi-Square Tests } \\
\hline & Value & df & Asymp. Sig. (2-sided) & Exact Sig. (2-sided) & Exact Sig. (1-sided) \\
\hline Pearson Chi-Square & 5.164 & 1 & .023 & & \\
\hline Continuity Correction & 4.100 & 1 & .043 & & \\
\hline Likelihood Ratio & 5.174 & 1 & .023 & .028 & .021 \\
\hline Fisher's Exact Test & & & & .024 & \\
\hline Linear-by-Linear Association & 5.091 & 1 & & & \\
\hline N of Valid Cases & 71 & & & & \\
\hline
\end{tabular}

From the Table 7 and 8, we can see the association of the Hypertension and knee osteoarthritis. Here, from the table above we can see that among 33 Hypertension positive respondents 19 had knee osteoarthritis and 14 had not. On the other hand, among 38 Hypertension negative respondents 8 had knee osteoarthritis and 30 had not. The above (Tables $7 \& 8$ ), the association of Hypertension and knee osteoarthritis of the respondent was evident. The chi-square has been done to see the association of the Hypertension and knee osteoarthritis. Where, Pearsons Chi-square ' $\mathrm{P}$ ' value $(\mathrm{P})=0.002$. From the above table we can understand there is association between Hypertension and knee osteoarthritis. For the association between Diabetes mellitus and knee osteoarthritis, ' $\mathrm{P}$ ' value was 0. 002. I.e., it is significant. We can say Hypertension and knee osteoarthritis do have association. For association P value should be smaller than 0.05 i.e. $(\mathrm{P}<0.05)$. Here, $0.002>0.05$. So, we

Table 8: Chi-square tests of Hypertension and knee osteoarthritis. can say that Hypertension and knee osteoarthritis are associated. Here, we can also say that Hypertension is the Tables $9 \& 10$ indicate the association of the smoking and knee osteoarthritis, among 12 smoker respondents 4 had knee osteoarthritis and 8 had not. On the other hand, among 59 nonsmoker respondents 23 had knee osteoarthritis and 36 had not.

Table 7: Association between Hypertension and knee osteoarthritis.

\begin{tabular}{|c|c|c|c|c|}
\hline \multicolumn{2}{|c|}{} & \multicolumn{2}{c|}{ Knee osteoarthritis } & \multirow{2}{*}{ Total } \\
\cline { 3 - 5 } \multicolumn{2}{|c|}{} & Yes & No & \\
\hline \multirow{3}{*}{ HTN } & Yes & 19 & 14 & 33 \\
\cline { 2 - 5 } & No & 8 & 30 & 38 \\
\hline \multicolumn{2}{|c|}{ Total } & 27 & 44 & 71 \\
\hline
\end{tabular}

\begin{tabular}{|c|c|c|c|c|c|}
\hline \multicolumn{7}{|c|}{ Chi-Square Tests } \\
\hline & Value & df & Asymp. Sig. (2-sided) & Exact Sig. (2-sided) & Exact Sig. (1-sided) \\
\hline Pearson Chi-Square & 9.997 & 1 & .002 & & \\
\hline Continuity Correction & 8.507 & 1 & .004 & .001 & \\
\hline Likelihood Ratio & 10.216 & 1 & & .003 & \\
\hline Fisher's Exact Test & & & .002 & & .002 \\
\hline Linear-by-Linear Association & 9.856 & 1 & & & \\
\hline N of Valid Cases & 71 & & & \\
\hline
\end{tabular}


Table 9: Association between smoking and knee osteoarthritis.

\begin{tabular}{|c|c|c|c|c|}
\hline \multicolumn{2}{|c|}{} & \multicolumn{2}{c|}{ Knee osteoarthritis } & \multirow{2}{*}{ Total } \\
\cline { 3 - 5 } \multicolumn{2}{|c|}{} & Yes & No & \\
\hline \multirow{3}{*}{ smoking } & Yes & 4 & 8 & 12 \\
\cline { 2 - 5 } & No & 23 & 36 & 59 \\
\hline \multicolumn{2}{|c|}{ Total } & 27 & 44 & 71 \\
\hline
\end{tabular}

The chi-square has been done to see the association of the smoking and knee osteoarthritis Table 10, where Pearsons Chisquare ' $P$ ' value $(P)=0.713$. From the above table we can understand there is no association between smoking and knee osteoarthritis.

Table 10: Chi-square tests of smoking and knee osteoarthritis.
For the association between smoking and knee osteoarthritis, ' $\mathrm{P}$ ' value was 0.713 . I.e., it is not significant. We can say smoking and knee osteoarthritis do not have any association. For association $P$ value should be smaller than 0.05 i.e. $(P<0.05)$. Here, $0.713>$ 0.05 . So, we can say that smoking and knee osteoarthritis are not associated. Here, we can also say that smoking is not risk factor for developing knee osteoarthritis. In the Tables $11 \& 12$, the association of the level of walking-standing and knee osteoarthritis are evident. Among 24 prolonged walking-standing respondents, 14 had knee osteoarthritis and 10 had not. On the other hand, among 47 less walking-standing respondents 13 had knee osteoarthritis and 34 had not.

\begin{tabular}{|c|c|c|c|c|c|}
\hline \multicolumn{7}{|c|}{ Chi-Square Tests } \\
\hline & Value & df & Asymp. Sig. (2-sided) & Exact Sig. (2-sided) & Exact Sig. (1-sided) \\
\hline Pearson Chi-Square & .135 & 1 & .713 & & \\
\hline Continuity Correction & .002 & 1 & .967 & & \\
\hline Likelihood Ratio & .137 & 1 & .711 & & .490 \\
\hline Fisher's Exact Test & & & & .715 & \\
\hline Linear-by-Linear Association & .133 & 1 & & & \\
\hline N of Valid Cases & 71 & & & & \\
\hline
\end{tabular}

Table 11: Association between level of walking-standing and knee osteoarthritis.

\begin{tabular}{|c|c|c|c|c|}
\hline \multicolumn{2}{|c|}{} & \multicolumn{2}{|c|}{ Knee osteoarthritis } & \multirow{2}{*}{ Total } \\
\cline { 3 - 5 } \multicolumn{2}{|c|}{} & Yes & 10 & 24 \\
\hline \multirow{2}{*}{ Level of walking-standing } & More & 14 & 34 & 47 \\
\cline { 2 - 5 } & Less & 13 & 44 & 71 \\
\hline Total & & 27 & & 24 \\
\hline
\end{tabular}

The above chi-square Table 12, is the association of level of walking-standing and knee osteoarthritis of the respondent. Where, Pearsons Chi-square ' $\mathrm{P}$ ' value $(\mathrm{P})=0.012$. From the above table we can understand there is association between level of walkingstanding and knee osteoarthritis. For the association between level of walking-standing and knee osteoarthritis, 'P' value was 0. 012 .

For association $\mathrm{P}$ value should be smaller than 0.05 i.e. $(\mathrm{P}<0.05)$. Here, $0.012>0.05$. so, we can say that level of walking-standing and knee osteoarthritis are associated. Here, we can also say that level of walking-standing is risk factor for developing knee osteoarthritis [32].

Table 12: Chi-square tests of level of walking-standing and knee osteoarthritis.

\begin{tabular}{|c|c|c|c|c|c|}
\hline \multicolumn{7}{|c|}{ Chi-Square Tests } \\
\hline & Value & df & Asymp. Sig. (2-sided) & Exact Sig. (2-sided) & Exact Sig. (1-sided) \\
\hline Pearson Chi-Square & 6.343 & 1 & .012 & & \\
\hline Continuity Correction & 5.108 & 1 & .024 & & \\
\hline Likelihood Ratio & 6.283 & 1 & .012 & & .019 \\
\hline Fisher's Exact Test & & & & .012 & .012 \\
\hline Linear-by-Linear Association & 6.254 & 1 & & & \\
\hline N of Valid Cases & 71 & & & & \\
\hline
\end{tabular}

\section{Discussion}

The present study observed that the percentage of people with osteoarthritis increased as the age increases. This observation is similar to that in a study done in south Delhi and at other places.
OA was more in women compared to men in our study $65.7 \%$ vs. $34.3 \%$ respectively). This difference can be possibly due to the lack of physical activity, mobility, social issues especially in our region and higher prevalence of obesity among women in general. Family history of OA was present in a few 26/102 (25.5\%) of our 
study subjects [33]. In the present study, most men had more occupational knee bending compared to women (40\% vs. $23.9 \%$ ). This can be due to the fact that most of the women in our study were homemakers. A study done by Cooper et al. [34] found that occupational knee bending is a positive risk factor for development of OA knee. The odds of getting OA with increased occupational knee bending were significantly more than for those who had no knee bending. The odds ratio varied from 1.2 to 6.9 for different types of knee bending. In our study, history of knee injury preceding the OA was found in only $17 / 102(16.7 \%)$ study subjects. Weight control significantly affected the risk of developing knee Osteoarthritis and demonstrated their action between joint injury and osteoarthritis of the knee as early as 1958 [35-40].

\section{Diagnosis}

Definitive diagnosis is mainly accomplished through careful analysis of the history of the patient and observation of joint alterations by X-ray and physical examination [41]. Osteoarthritis of the knee can be diagnosed mainly in two ways

a) Radiological Diagnosis Includes: Plain radiographs or X-rays: X-rays can help in the diagnosis and may be the only special test required in the majority of cases. Bone density is either normal or increased (Osteoarthritis, 2006). Arthroscopy may show cartilage damage long before X-ray changes appear [42] MRI: It can demonstrate early cartilage change [43].

b) Pathological Diagnosis Includes: Blood test: In OA, the white blood cell count is usually less than 500 cells $\mathrm{mm} 2$ and is composed predominantly of mononuclear cells. In inflammatory aspirates the white blood cell count is usually greater than 2,000 per $\mathrm{mm} 2$ and the predominant cell type is usually the neutrophil (Hinton et al., 2002). The ESR and Rheumatoid factor and antinuclear antibodies are negative [44].

\section{Physiotherapy Diagnosis}

Physiotherapists use Clarke's sign. This test assesses the presence of patella-femoral dysfunction and use of Apprehension test for patellar subluxation and dislocation [45].

\section{Medical Management}

The American College of Rheumatology (2001) emphasizes that drug therapy for $\mathrm{OA}$ is best used as an addition to nonpharmacological treatment. Oral, topical and intra-articular agents are available for the treatment of OA. Acetaminophen is comparable in efficacy to non-steroidal anti- inflammatory drugs (NSAIDs) for controlling mild to moderate OA pain. Though Acetaminophen is the first line analgesics, many patients who may respond better to NSAID [46]. For the patients at high risk of GI complications a Cox2 inhibitor may be considered. For the patients with severe pain who do not respond to or have contraindications to other agents, tramadol or another opioid (e.g., codeine plus acetaminophen) may be considered. Sometimes intra-articular steroids injection are given for $\mathrm{OA}$ of knee joint but it has serious side effects such as infection of the joint [47].

\section{Physiotherapy Management of Osteoarthritis}

There is a good evidence to support the use of a number of physiotherapy interventions in the management of knee joint osteoarthritis [48]. The management of OA depends on the joint involvement, the stage of the disorder, the severity of the symptoms, age of the patient and his or her functional needs [49-55].

\section{PRP as a Treatment of Knee Osteoarthritis}

In cases of early $\mathrm{OA}$, the major treatment option is a conservative therapy for pain reduction because there is nothing known to stop the progression of degeneration sequences. Recently, new reparative methods, including Platelet-Rich Plasma (PRP) treatment, to treat early $\mathrm{OA}$ and cartilage lesions are getting clinical attention. PRP consists of a volume of plasma with a platelet concentration above baseline values that are obtained from the patient's own blood. As such, PRP is safe from immune reaction and blood diseases because it is obtained from autologous blood and the application of PRP in the outpatient clinic is possible.

\section{Conclusion}

The number of sufferer of knee osteoarthritis is increasing day by day due to lack of awareness. It affects a large number of individual who become a burden for themselves and make a devastating effect on their family and society as well as in whole country. It was observed that there is relationship between age, sex and BMI with OA. So, it is recommended that preventive measures can be taken in the earlier age groups so OA can be prevented and to conduct research on other musculoskeletal and problems on knee area where physiotherapist can work.

\section{Acknowledgement}

We like to express my sincere, and heartfelt gratitude to the Public Health Department, American International University Bangladesh permitted and supported me to conduct this research. This research would not have been possible without support from Surecell Medical BD LTD.

\section{References}

1. (2001) American college of Rheumatology. Managing osteoarthritis: New ACR Guidelines.

2. Anderson JJ, Naimark A, Hannan MT, Kannel WB, Meenan RF (2007) Does smoking protect against osteoarthritis? Arthritis Rheumatology 32(2): 166-172.

3. Andre K, Gebhardt H, Lievers F, Engelhardt LV, David A (2008) Individual and occupational risk factors for knee osteoarthritis. BMC Musculoskeletal Disorders 9(26): 1471-1474.

4. (2001) Arthritis Prevalence and Activity Limitation United States.

5. (2011) Australian Physiotherapy Association, 2001.

6. Bennell KL, Hinman RS, Metcalf BR, Buchbinder R, McConnell J (2005) Efficiency of physiotherapy management of knee joint osteoarthritis: 
a randomized, double blind, placebo controlled trial. Annals of the Pneumatic Diseases 64(6): 906-912.

7. Brandit K (2001) Harrison's principles of internal medicine. McGrawHill company, USA.

8. Braunwald SL, Hauser AS, Fauci DL, Loggo DL, Kasper JL (2004) Osteoarthritis. Mosby international, London.

9. Bulstrod J, Baar MEV, Dekker J, Bijl D, Bijlsma JWJ (2001) Effectiveness of exercises in patients with osteoarthritis of hip or knee: nine months follow up. Annals of the Rheumatic Diseases 60(3): 1123-1130.

10. Cailliet R (1992) Knee pain and Disability. In Cailliet R (Eds.), (3rd edn.), Jaypee Brothers, New Delhi.

11. Carfagno DG, Ellenbecker TS (2002) Osteoarthritis of Glenohumeral joint. The physician and sports medicine 30(4): 13.

12. Chadwick A (1998) Rheumatology Physiotherapy. Mosby international, London.

13. Chamberlain MA (1997) Osteoarthritis. Rehabilitation of the physically disabled Adult. In Chamberlain MA(Eds.), Stanley Thones Publishers Ltd, United Kingdom.

14. Chitnavas J, Carr A (2002) Osteoarthritis. Oxford textbook of orthopedic and trauma. In Chitnavas J, Carr A(Eds.), Oxford university press, NewYork, USA.

15. Chitnavis J, Carr A (2002) Oxford textbook of orthopedic and trauma. In: Chitnavis J, Carr A (Eds.), Oxford university press, NewYork, USA.

16. Cicuttini FM, Baker JR, Spector TD (1996) The association of obesity with osteoarthritis of the hand and knee in women: a twin study. Journal of Rheumatology 23(4): 1221-1226.

17. Coggon D, Croft P, Kellingray S, Hannan MT (2000) Occupational physical activities and osteoarthritis of the knee. Arthritis Rheumatism 43(3):1443-1449.

18. Connor MI (2007) Sex differences in osteoarthritis of the hip and knee. Journal of American Academy Orthopedic Surgery 15(1): 22-25.

19. Cooper C, Snow S, McAlindon TE, Naimark A (2000) Risk factors for the incidence and progression of radiographic knee osteoarthritis. Arthritis Rheumatology 43(5): 995-1000.

20. Datta A (2000) Essential of Human Anatomy Superior and Inferior Extremities. In: Datta A(Eds.), (2 ${ }^{\text {nd }}$ edn.). Current Books Internationals, Mumbai, India.

21. Doherty M (2002) Musculoskeletal disorders. Davidson's principles and practice of medicine. In Doherty M (Eds.), (19 ${ }^{\text {th }}$ edn.). Churchill Livingstone, London.

22. Ebnezer J (2003) Essential of orthopaedics for physiotherapists: Disorders of joints. In: Ebnezer J (Eds), ( $2^{\text {nd }}$ edn.). Jaypee, New Delhi, India.

23. Felson D (2005) Knee Osteoarthritis: does physiotherapy help.

24. Felson DT (1996) Does excess weight cause osteoarthritis and if so, why? Annals of the Rheumatic Diseases 55(9): 668-670

25. Felson DT, Zhang Y, Hannan MT, Naimark A, Weissman B (1997) Risk Factors for Incident Radiographic Knee Osteoarthritis in the elderly. Arthritis Rheum 40(9): 728-733.

26. Foley A, Halbert J, Hewitt T, Crotty M (2003) Does hydrotherapy improve strength and physical function in patients with osteoarthritis-a randomized controlled trial comparing a gym based and a hydrotherapy based strengthening programme. Annals of the Rheumatic Disease 62(12): 1162-1167.

27. Guccione AA, Minor MA (2001) Physical Rehabilitation Assessment and Treatment. In Guccione AA, Minor MA(Eds.), (5 ${ }^{\text {th }}$ edn.) Jaypee Brothers, New Delhi, India.
28. Haq SA, Davatchi F, Dahaghin S, Islam N (2010) Development of a questionnaire for identification of the risk factor for osteoarthritis of the knee in developing countries: A pilot study in Iran and Bangladesh. International journal of rheumatic diseases 13: 203-214.

29. Hilt NE, Cogburn SB (1994) Manual of Orthopaedic: Joint disease and disorders. The CV Mosby Company, London.

30. Hinton R, Moody RI, Davis AW, Thomas SA (2002) Osteoarthritis: Diagnosis and therapeutic considerations. American academy of family physicians 65(5): 112-120.

31. Holman H, Lorig K (2004) Patient Self-Management: A key to Effectiveness and Efficiency in Care of Chronic Disease. Public Health Reports 119(3): 239-245.

32. Hurley M, Dziedzic K, Bearne L, Sim J, Bury T (2002) The clinical and cost effectiveness of physiotherapy in the management of older people with common rheumatological conditions. The chartered society of physiotherapy 12(4): 221-230

33. Juhakoski R, Heliovaara M, Impivaara O, Kroger H, Knekt P (2009) Risk Factors for the Development of Hip Osteoarthritis: a population-based prospective study. Rheumatology 48(1): 83-87.

34. Kumar P, Clark M (2002) Clinical medicine: Rheumatology and bone diseases. In: Kumar P, Clark M (Eds.), ( $5^{\text {th }}$ edn.), Philadelphia, London.

35. Kumar P, Clark M (2002) Rheumatology and bone disease. In: Kumar P, Clark M (Eds.), ( $5^{\text {th }}$ edn.). W.B. Saunders, London.

36. Kwan D, Papoushek C (2002) Osteoarthritis. CMAJ 163(8): 999-1005.

37. Laree E (1996) Osteoarthritis in relation to age. The journal of the American Society of Consultant Pharmacists 11: 1-3.

38. MacAulay D (2003) Managing osteoarthritis of the knee.

39. Magee DJ (1997) Orhopaedic Physical Assessment: knee. W.B. Saunders Company, Philadelphia.

40. Marks R, Ghnagaraja S, Ghassemin M (2000) Ultrasound for osteoarthritis of the knee. Physiotherapy journal 86(6): 458-470.

41. Mounach A, Nouijai A, Ghozlani I (2008) Risk factors for knee osteoarthritis in Morocco: A case control study. Clinical Rheumatology 27(3): 323-326.

42.(2002) National Institute of Arthritis and Musculoskeletal and Skin Diseases, 2002. Osteoarthritis.

43. (2006) Osteoarthritis.

44. Pascual E (2003) Shoes and lower limb osteoarthritis. Journal of Epidemiology and community health 57: 763-765

45. Paul DC, Saadullah M (1991) Role of women in homestead of small farm category in an area of Jessore. Livestock Research for Rural Development 3: $1-2$.

46. Porter SB (2003) Tidy's physiotherapy: Osteoarthritis. In Porter SB (Eds.), (13 ${ }^{\text {th }}$ edn.), Butterworth-Heinemann, Oxford.

47. Rashid MA, Moyeenuzzaman l, Islam k, Samad MA, Haque AS (1997) A study of effectiveness of diathermy on patients with osteoarthritis of knee joint-A study on 60 cases. The Journal of Bangladesh Orthopedic Society 12(1): 12-16.

48. Reilly SO (2001) The treatment of osteoarthritis. CPD Rheumatology 2(1): 1416-1420.

49. Solomon L, Warwick DJ, Nayagam S (2001) Apley's system of Orthopedics and fracture. In: Solomon L, Warwick DJ, Nayagam S (Eds.), ( $8^{\text {th }}$ edn.). Hodder headline group, London.

50. (2005) Statistics by Country Osteoarthritis. http://www.Niams.Gov/ index.html. 
51. Stenmark J (1995) Musculoskeletal Physiotherapy-Clinical Science and Practice. In Stenmark J (Eds.), Butterworth Heinemann Ltd, Oxford, United Kingdom.

52. Thomas C (1998) Taber's Cyclopedic Medical Dictionary. In Thomas C (Eds.), Jaypee brothers' medical publishers, India.

53. Thomson A, Skinner A, Piercy J (1991) Tidy's Physiotherapy. In: Thomson A, Skinner A, Piercy J(Eds.), (12 ${ }^{\text {th }}$ edn.). Butter-worth Heinemann, United Kingdom.

ISSN: 2574-1241

DOI: $10.26717 /$ BJSTR.2021.34.005567

Hamida Khanum. Biomed J Sci \& Tech Res

(c) (P) This work is licensed under Creative

Submission Link: https://biomedres.us/submit-manuscript.php
54. Thomson D (2001) Explanation into Effects of an Exercise Program on the lives of Elderly Female Fallers. Physiotherapy 67(2): 88-93.

55. William C (1996) Effectiveness an Exercise Program on Osteoarthritis. European Orthopedics Jour.

$\begin{array}{ll}\text { BIOMEDICAL } & \text { Assets of Publishing with us } \\ \text { RESEARCHES } & \text { - Global archiving of articles } \\ & \text { - Immediate, unrestricted online access } \\ & \text { - Rigorous Peer Review Process } \\ & \end{array}$

